\title{
New trends of the economy: a case of digital energy
}

\author{
Aysel Guliyeva ${ }^{1}$, Adalat Bayramov ${ }^{2}$, Sabir Taghizade ${ }^{2}$ \\ ${ }^{1}$ International Economy Department, Azerbaijan State University of Economics (UNEC), 6, \\ Istiglaliyyat str., AZ1001, Baku, Azerbaijan \\ ${ }^{2}$ SABAH CENTER, Azerbaijan State University of Economics (UNEC), 6, Istiglaliyyat str., AZ1001, \\ Baku, Azerbaijan
}

\begin{abstract}
This paper studies the concept of "digital energy", its own unique content, or maybe is it just a fashionable designation for what has been done in the industry since the massive spread of computer technology. Why use the neologism "digitalization" instead of the well-known and well-defined term "automation"? Some sources insist on having its own unique content in terms of "digital energy" and "digitalization". This post sets out our working hypothesis - five distinguishing features by which one can understand whether we are working with the concept of "digital energy" or with something else. In digital energy as a part of the digital economy, the main concept is "economy". The essence of digital energy is the reassembly and development of a set of industrial and economic relations in the industry based on digital approaches and means. Consequently, the essence of digital energy is the reassembly and development of a set of industrial and economic relations in the industry based on digital approaches and means. So, in the phrase "digital economy" (and hence "digital energy"), the defining word is "economy", and the adjective "digital" only indicates the means to achieve the goal.
\end{abstract}

\section{Introduction}

The main task of digital energy is to eliminate the sharply growing costs of integrating distributed energy and market transactions [1]. The emergence of a digital platform in any industry significantly reduces transaction costs. And what, in fact, is the goal? According to leading experts, the essence of the modern era is the replacement by machines of ineffective transactions requiring routine human participation from economic and social life. The emergence of a digital platform in any industry leads to a significant reduction in transaction costs and an acceleration of the operational cycles of its participants [2, 3]. Energy is no exception. Digital transformation (digitalization) in the energy sector is, first of all, the creation of new business models, services and markets based on the capabilities of the digital economy [4]. A simple example from another industry: creating an automated dispatch system for a taxi fleet is automation, but Uber, which essentially creates a new business

\footnotetext{
*Corresponding author: aysel.guliyeva10@gmail.com
} 
model for the same service, without being a taxi fleet and not owning a single car, and makes it cheaper, more convenient and safer is digitalization. The same is true in digital energy: it is important to define a new business model whose potential is unlocked by pervasive communications, machine-to-machine communications and digital modeling. Many digital business models have been developed: demand aggregators, virtual power plants, virtual distributed energy storage, energy hedging, etc. [5, 6].

A digital energy project always involves the use of digital models of fragments of the real world. A characteristic feature of the digital economy (energy) is the creation of new business models that combine the physical and digital worlds. And such unification is possible when smart machines begin to form and use digital models of the physical world. This is what ensures the independence of machine decision making in near real time. Sometimes it seems that for new business models of digital energy, the emergence of means of informing a person who will still make decisions for himself is enough. But experimental projects have shown that after a while people cease to be interested in new patterns of behavior that impose too high demands on them [7, 8]. Cyber-physical systems need to take over the initiative, which should act as a miraculous laxative from one old advertisement "without disturbing human sleep." And for this, machines must be guided not by standards and rigid algorithms, but by goals set by people and digital models of fragments of the real world. "Digitalization" is the liberation of a person from machine functions and the emergence of new, more creative forms of employment $[9,10]$.

In high-tech industries, there is a high additional load in adjacent areas of activity. It is still poorly described how the digital economy (energy) affects people and their employments in socially useful work. Often people record their fears of being unemployed and unemployed. To this, experts in the digital economy say that high-tech industries create a high additional load in adjacent areas of activity.

But there are deeper answers to questions about the changing role of humans in the digital world. Back in the discussions of the 1960s, it was discussed that the meaning of the cybernetic/digital transition is not to create a machine that would be smarter, stronger and more perfect than a person, but to make the living person again smarter and stronger than anything else [11]. The world of machines he created, which got out of his control and enslaved him. The task is to transform a person from a raw material and a means of technical progress, from a detail of "production for the sake of production" into the highest goal of this production, into an end in itself. This means that a project in the field of digital energy is always the emergence of a new truly human labor with a large share of scientific, technical, artistic and social creativity [12].

\section{Materials and methods}

Digital energy is the transaction machines of new markets, models and services. The digital transition is often referred to as a new technological revolution [13]. But it would be strange to call a revolution a phenomenon and processes that have long become commonplace. Automation of production, technological and management processes is the greatest achievement of the second half of the $20^{\text {th }}$ century. Process control systems for power plants, dispatch control systems, automation of active energy devices, accounting and office automation systems - all these are important and relevant areas of the evolutionary development of the industry [14]. But this is not a new technological revolution; it is not a digital economy or digital energy. It seems that it is precisely in the change in the ways of organizing economic relations, leading to the effective involvement of millions of new subjects and the smart machines behind them, that a new qualitative leap should take place. First of all, digitalization will not be subject to technical systems and internal business processes, but the relationship between people, companies and institutions. Digital energy is, 
first of all, the transaction machines of new markets, business models and services. The New World changes its energy circuits and there are several reasons for this. And the first is the active relocation of people to cities.

In 2012, the share of the world's urban population exceeded $50 \%$. By $2020,60 \%$ of the population is expected to live in cities in China alone [15]. The growth of old and the emergence of new cities creates a demand for the transition to urban energy of a new generation: with a high concentration of capacities, a margin of safety, occupation of a small area, an acceptable price for connecting to the infrastructure and differentiated cost of electricity for different groups of consumers.

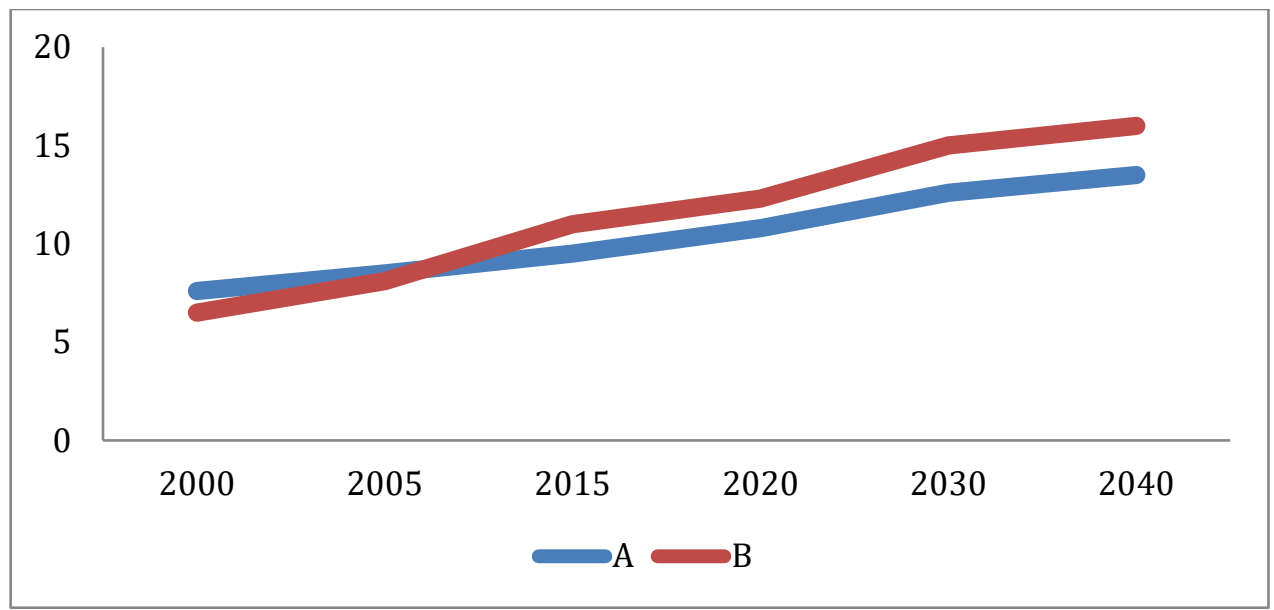

Fig. 1. A) Non-OECD countries, B) OECD countries. Overall growth in electricity production, 2000-2040 [16]

In addition, energy solutions must be environmentally friendly. According to the International Energy Agency, the electricity industry is the source of $42 \%$ of anthropogenic greenhouse gas emissions and a significant source of pollutant emissions [17]. Cities with a high concentration of gas and especially coal power generation are already today hazardous to health and cannot grow.

\section{Empirical model}

The development in modern cities of digital systems, additive and high-precision industries, which are highly sensitive to the reliability of power supply and the quality of electricity, determine the qualitative change in demand. According to forecasts, by 2030, of the customers in the developed countries will consume up to $30 \%$ of electricity [18].

The growing requirements for the quality of energy and the environmental friendliness of its production will be accompanied by the need for a sharp increase in its volumes. According to calculations, by 2035 additional electricity consumers will be: 1.3 billion people who currently do not have access to electricity; 2.7 billion people who cook with wood; another 1.6 billion people due to population growth in the world $[19,20]$. This will lead to the fact that the consumption of electricity on the planet will grow one and a half times, and its geography will change greatly. 


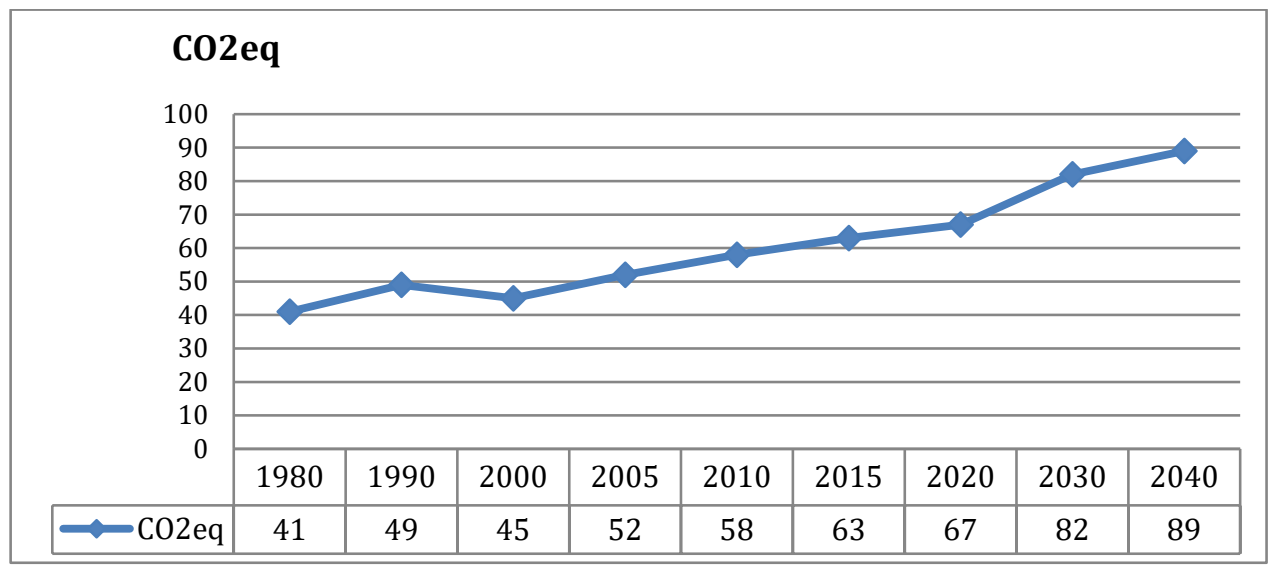

Fig. 2. Greenhouse gas emissions and target reduction levels to keep global warming within

The question arises - where to find finances to solve such a large-scale task? Traditional industrial-type energy systems were built in a situation of high savings and strong government investment, as well as investments from private sources. Today, this is not the case: the level of savings has fallen over the past 30 years, and countries are overwhelmed by the costs of servicing financial deficits and social obligations. Bank capital, on the other hand, due to changes in the model of energy markets and the presence of more attractive investment objects, does not show interest in such projects.

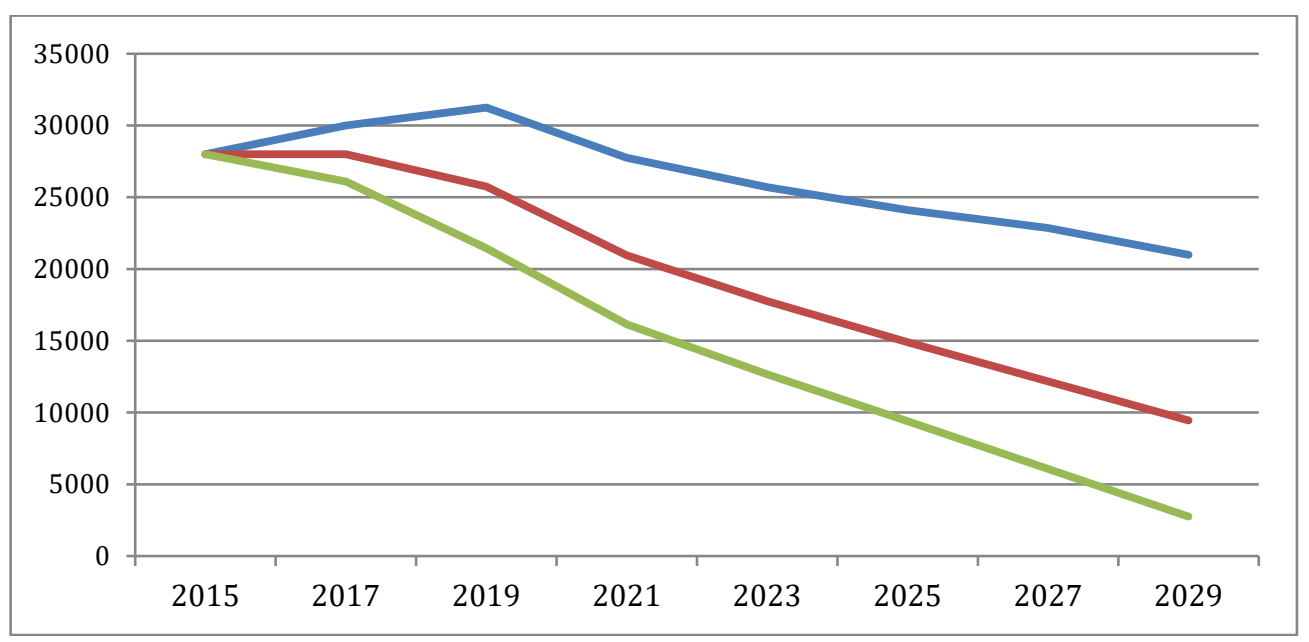

Fig. 3. Forecast balance of demand for power supply 


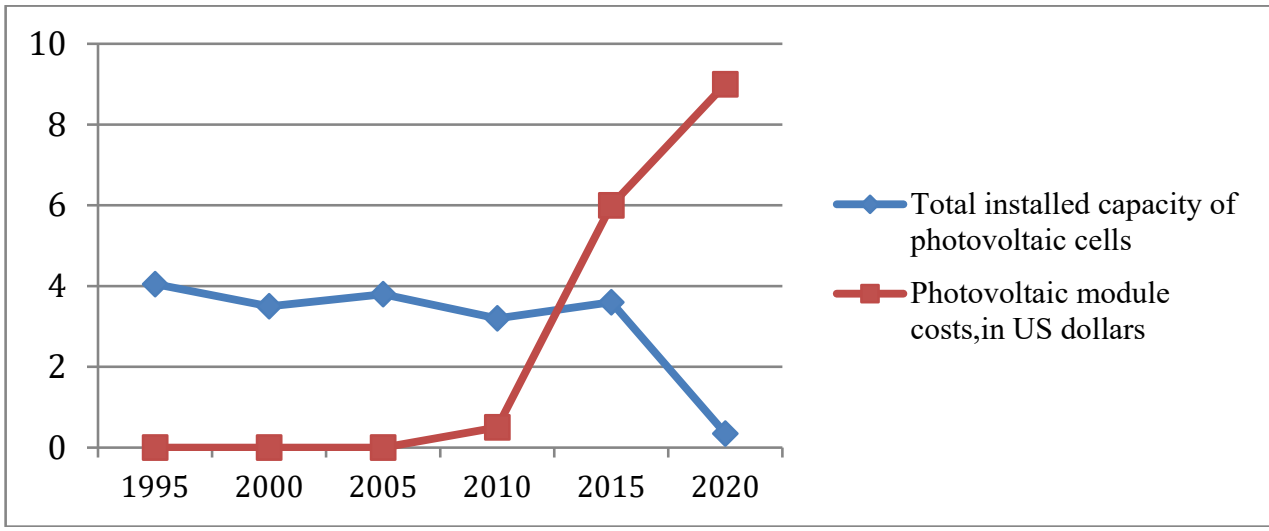

Fig. 4. The speed of development of photovoltaic technologies: the ratio of the installed capacity and the cost of modules.

\section{Conclusions}

Thence, the question arises: what to do about it all? How to meet the growing demand, including for high-quality and environmentally friendly power industry in the absence of funding and long project implementation terms? For this, a strategy was developed, the socalled "energy transition", which became possible due to the following technological and market trends.

First, there is a reduction in the cost of new technologies for the use of renewable energy sources (RES). For example, the cost of wind turbines from 1980 to 2013 decreased by 10 times, and photovoltaic modules in 2014 fell in price by $75 \%$ compared to the 2009 level.

Second, the share of distributed energy is growing, associated with the speed and ease of installation and maintenance of equipment, and the comparable cost with connection to the public network. In the case of further improvement of storage systems (accumulators) of electricity, one can expect a sharp increase in this trend.

Third, energy saving technologies and practices are being disseminated. According to the IEA, the energy intensity of the GDP of the organization's member countries is decreasing by $2 \%$ annually.

Fourth, the proliferation of digital networks and intelligent control systems, as a result of which the network infrastructure is being transformed into a new cyber-physical platform for flexible and efficient energy supply to consumers.

Fifth, consumers themselves are turning into suppliers of electricity and are in conflict with the norms of traditional regulation of the electricity market, and even demand "Energy Democracy". For example, in Germany, half of the renewable energy market is controlled by households and farmers.

Sixth, the emergence of new technologies in the financial sector (block chain, Smart Contract, Decentralized Autonomous Organizations), which creates potential opportunities for attracting new private investments in the energy sector and the formation of various energy exchange practices.

All this makes it possible to start the energy transition today. Moreover, not only in developed countries, but also in developing countries, which simply cannot build a traditional power system due to its high cost (for example, the cost of the US power system is $\$ 1$ trillion), the need for complex competencies and a large number of skilled labor for management and maintenance. 
What will the energy transition look like in general terms? First, technically, this is the creation of a more flexible architecture of energy systems due to distributed generation, the development of "smart" grids and the energy storage market, as well as due to the emergence of active ("smart") consumers. Secondly, it is the formation of a new business model for the electric power industry: instead of the traditional value added chain "generation - trading transmission - distribution", the model of the "Internet of energy" and the provision of services in a new interactive environment. Thirdly, this is a change in state regulation - a gradual transition from support for renewable energy sources and competition in the electricity market to consumer support, integration of local solutions; from energy supply to "interconnection of capacities" within the framework of the "Internet of Energy", the transition to a "flexible market".

\section{References}

1. J. Niu, Z. Tian, J. Zhu, L. Yue, Energy Conversion and Management, 208, 112575 (2020)

2. J. Mendling, G. Decker, R. Hull, H. Reijers, I. Weber, Communications of the Association for Information Systems, 43(1), 19 (2018)

3. W. Strielkowski, Social Impacts of Smart Grids: The Future of Smart Grids and Energy Market Design (2019)

4. A. Alekseev, S. Lobova, A. Bogoviz, Y. Ragulina, International Journal of Energy Economics and Policy, 9(5), 274-280 (2019)

5. V. Munyon, W. Bowen, J. Holcombe, Energy Research \& Social Science, 38, 19-27 (2018)

6. J. Yun, X. Zhao, J. Wu, J. Yi, K. Park, W. Jung, Sustainability, 12(5), 1883 (2020)

7. L. Groeger, K. Bruce, I. Rolfe, Industrial Marketing Management, 77, 102-115 (2019)

8. E. Clemons, New Patterns of Power and Profit: A Strategist's Guide to Competitive Advantage in the Age of Digital Transformation (2018)

9. J. Zhou, P. Li, Y. Zhou, B. Wang, J. Zang, L. Meng, Engineering, 4(1), 11-20 (2018)

10. F. Miele, I. Tirabeni, Sociology Compass, 14(6), e12795 (2020)

11. J. Carrasco-Sáez, M. Careaga Butter, M. Badilla-Quintana, Sustainability, 9(12), 2258 (2017)

12. W. Strielkowski, E. Volkova, L. Pushkareva, D. Streimikiene, Energies, 12(7), 1392 (2019)

13. M. Loock, Energy research \& social science, 69, 101740 (2020)

14. D. Horváth, R. Szabó, Technological Forecasting and Social Change, 146, 119-132 (2019)

15. Y. Li, X. Kong, Z. Zhu, Sustainable Cities and Society, 61, 102326 (2020)

16. OECD, https://www.oecd.org (2020)

17. IEA, https://www.iea.org/reports/global-energy-co2-status-report-2019 (2019)

18. Energypost, https://energypost.eu/end-energiewende (2019)

19. Y. Wei, H. Liao, Global Energy Development and Energy Poverty (2018)

20. M. Rajaeifar, H. Ghanavati, B. Dashti, R. Heijungs, M. Aghbashlo, M. Tabatabaei, Renewable and Sustainable Energy Reviews, 79, 414-439 (2017) 